\title{
Methodology for Calculation of the Marginal Emission Rates from a Complex Cogeneration Facility compared with that of the co-located NY ISO Bus
}

\author{
Richard Tabors \\ Aleksandr Rudkevich \\ Hua $\mathrm{He}$ \\ Ninad Kumthekar \\ Xindi Li \\ Tabors Caramanis Rudkevich and Newton Energy Group \\ Newton, Massachusetts \\ rtabors@tcr-us.com \\ arudkevich@negll.com hhe@tcr-us.com nkumthekar@tcr-us.com \\ xindi@tcr-us.com

\begin{tabular}{|c|c|c|}
\hline Robert Bland & $\begin{array}{l}\text { Garret Quist } \\
\text { Cornell University } \\
\text { Ithaca, New York }\end{array}$ & Joshua LaPenna \\
\hline rb2@cornell.edu & gq29@cornell.com & jj1334@cornell.com \\
\hline
\end{tabular}

\begin{abstract}
Cogeneration facilities at commercial and institutional locations are significant emitters carbon dioxide. Many large universities, hospitals and large commercial complexes maintain combined heat and power facilities that are interfaced with wholesale power markets. These facilities both buy and sell electricity in the organized markets while maintaining what is their principle function of provision of thermal energy for heating and cooling. In this paper we provide the theoretical background to calculation of Marginal Emission Rates (MERs), provide an overview of the optimal operation of those facilities, and present the results of a detailed case analysis of the results of a comparison of the MER of an operating cogeneration facility at Cornell University compared with the MER for consumption of electricity at the closest wholesale bus of the New York Independent System Operator (NYISO).
\end{abstract}

\section{Introduction}

The carbon emissions of the continental US electric power sector have been decreasing significantly in over the past decade. The electric power sector as a whole has declined from a peak of 2424 million metric tons of $\mathrm{CO}_{2}$ in 2007 to 1763 million metric tons in 2018 representing a decline in percentage of total US emissions from $40.4 \%$ to $33.5 \%{ }^{1} \quad$ Large-scale combined heat and power installations such as institutional cogeneration facilities are being challenged to demonstrate that they too are reducing emissions, i.e., reducing their carbon footprint and, critically, that they are doing so in a manner that assures maximum economic efficiency of their operations.

The objective of this paper is twofold. The first is to define a mathematically consistent methodology by which a major institutional cogeneration facility such as Cornell University can measure its carbon footprint relative to what its footprint for electric consumption would be had it purchased all required electricity from the grid. The second is to present a case study that compares the hourly emissions of a major cogeneration facility (Cornell's Energy Plant) against the marginal emissions at the Cornell node of the NYISO power system. Marginal emissions from the cogeneration facility vary as a function of Cornell's demand for heat and power and as a function of the economic benefits of purchase from or sale of electricity to the NYISO wholesale market.

In response to the first objective, the discussion that follows provides:

- The theoretical background to the calculation of Marginal Emission Rates (MERs) from cogeneration facilities.

- A description of operational complexity of cogeneration facilities, as this impacts the calculation of MERs; and

${ }^{1}$ EIA Monthly Energy Review, May 29, 2019 Tables 12.1 and 12.6. 
- An introduction to the cloud-based system ENELYTIX - used to calculate MERs for the Cornell case study. ${ }^{2}$

The second objective is met through the demonstration of the analytic method calculating and comparing the results of the case analysis of the Cornell Energy Plant (CEP) with the calculated MER of NYISO at the nearest wholesale bus.

The case study and data provided in this paper was developed through the impetus of Cornell University and the requirements of the university's Climate Action Plan established in 2009 (and revised in 2015). Following the introduction of the action plan:

- In August 2016 Cornell published the 'Climate Neutral Campus Energy Alternatives Report (CNCEAR)' followed by 'Options for Achieving a Carbon Neutral Campus by 2035' in September 2016 which provides a roadmap of achieving carbon neutrality and identifies 'campus energy supply' as one of the four key target areas.

- In February 2019, Cornell issued an RFP for a Marginal Emission Rates (MER) study to assess locational Marginal Emissions Rates (MERs) at Cornell's Ithaca campus, specifically from the Central Energy Plant (CEP), a complex cogeneration facility providing both heat and power to the campus as well as trading power with the wholesale market of New York.

The objective of the CEP study was to assess and establish the MERs associated with the operation of the Cornell CEP and to be able to compare them against the NYISO grid MERs. It is important to note at this point that the NYISO is preparing to move forward with a MER structure referred to as LMPC (Locational Marginal Price: Carbon) that calculates the MER identically to the method used in this paper, and then multiplies the mass of $\mathrm{CO}_{2}$ by a cost of $\mathrm{CO}_{2}$.

\section{Marginal Emission Rate: The Logic}

The advent of greater concern for climate change and specifically $\mathrm{CO}_{2}$ emissions has led to a number of studies and methodologies attempting to quantify the environmental impact of individual actions. The result has been a myriad of papers focused on average emissions; discussions of "Green Products" and "Green Companies." [1,2,3] In addition, one early article [4] has led to the development of a commercial product, WattTime. [5]

${ }^{2}$ ENELYTIX (powered by PSO) is a cloud-based SCUC SCD power system simulation modeling tool available through Newton Energy Group, Boston, MA.
There have been only a limited number of marginal methodologies proposed and many of those were developed by a subset of the authors of this paper or by others based on the theory developed by the authors. [5, 6,7] The mathematically defendable Marginal Emission Rate (MER) calculation methodology for both electric consumption and renewables generation address both the physics and the economics of carbon from the power system by starting from the basics in the same manner as the original developers approached the development and implementation of the concepts that led to Locational Marginal Pricing (LMP). The critical understanding in MER as in LMP is that the physical (quantity) and economic (dollar) value in both instances is a function of Where, When and What.

The calculation of an electricity consuming entity's carbon foot print is a function of the marginal change in power system emissions caused by an incremental or decremental unit of energy consumed at the location the WHERE - and at the time - the WHEN that the energy is consumed. The WHAT is quantity -- the change in system-wide carbon emissions attributable to an incremental or decremental change in the entity's consumption expressed as the Marginal Emissions Rate. These interval or hourly specific marginal changes can be summed over an hour a week or a year to identify the total impact - a carbon footprint or evaluated to identify the impact of specific policies or investments.

The detailed engineering and mathematical analysis of $\mathrm{CO}_{2}$ emissions in constrained power networks presented in this paper was initially developed in [6], which introduced the concept of marginal carbon intensity (MCI) of electricity consumption and subsequently reported in [7 and 8]. These studies demonstrated the time-dependent and locational properties of marginal carbon emissions within a networked power system.

The conceptual structure of MER provides analysis needed to calculate the locational carbon footprint of loads, generators and constrained transmission facilities within a power system. In this paper, we provide a formal definition of the carbon footprint of any system element, derive mathematical formulas underlying its calculation and establish the relationship between the total systemwide mass of carbon emissions and carbon footprints of system elements.

To begin, consider an electrical grid as a whole and assume that at any moment that we can measure the total mass of carbon emissions released by all interconnected generators. Thus, let $\mathrm{C}(t)$ be total mass of $\mathrm{CO}_{2}$ emissions produced by the electrical grid measured in 
tons of $\mathrm{CO}_{2}$ over time period $t$. The MER (introduced as Marginal Carbon Intensity (MCI) in [1]) is equal to the increase or decrease in $\mathrm{CO}_{2}$ emissions in the electrical network in response to an infinitesimal increase or decrease in electricity supply or demand and measured in short tons (sh. tn/MWh).

MER depends on the time and location of the applied demand reduction measure. A larger MER for a given location and time indicates a greater sensitivity in the total carbon emission volume in response to a change in electricity supply or demand. A positive value of MER implies that at a given location and time an increase/decrease in electricity demand causes increase/decrease in $\mathrm{CO} 2$ emissions in the power system. A negative value of MER implies that at a given location and time changes in electricity supply or demand and $\mathrm{CO}_{2}$ emissions move in opposite directions. (A statistical analysis of demand reduction measures relying on real-time prices reported in [5] indicates that demand reduction could result in an increase in emissions, in this case $\mathrm{NO}_{\mathrm{x}}$ and $\mathrm{SO}_{2}$ ).

\section{Marginal Emission Rate: Calculation}

In this paper we develop hourly marginal emission rates for the electric grid at the Maple Avenue Substation in Ithaca based on the methodology developed by Alex Rudkevich and Pablo Ruiz [5]. The theoretical underpinning and applications of this approach have been published in the Proceedings of Hawaii International Conference on System Sciences (HICSS) in 2010-2011 [1\&3] and in the Handbook of $\mathrm{CO}_{2}$ in Power Systems in 2012 [2]. These papers provide the mathematical derivations underlying the calculation of the grid's marginal emission rates at the greatest level of temporal and spatial granularity.

It is important to note that the NYISO has recently introduced the concept of the LBMP Carbon Impact (LBMPC) $[9,10]$. This concept is effectively identical to, and relies on the same technique as, the MER calculation method used in this study. NYISO's LBMPC and MER are related to each other with a simple formula:

\section{$L B M P_{C}=M E R \times P_{C}$ (the NYS assumed price of carbon)}

To forecast a potential impact on MER at any location, in this instance the CEP, it is necessary to be able to simulate the emission levels of the power system at any point in time and location. This LMER could, in theory, be computed through the analysis of marginal generating units and binding constraints on transmission using shift factor and loss factor decomposition. In practice, this is approach is very difficult to implement because marginal generating units are not often easily identified as they may be marginal either for energy or for reserves. The marginal units may be constrained based on energy-limited hydro or pumped storage units and it may not be possible to capture the optimized operation of phase shifters.

To the positive, these difficulties in modeling can be overcome given the basic relationship between MER and LBMP. Stated simply, at each location LBMP changes with small variations in $\mathrm{CO}_{2}$ in proportion to the MER at that location.

Estimating MER using a production cost modeling approach requires that one:

- Run the simulation for the system and compute the LBMPs for each location (all generators and all load areas) including a value for the price of $\mathrm{CO}_{2}$

- RERUN the dispatch using the same unit commitment as above with an incremental increase in the $\mathrm{CO}_{2}$ price and recompute the LBMPs.

- From the differences between the two runs estimate the MERs using:

$$
L M E R=\frac{\Delta L B M P}{\Delta \mathrm{CO}_{2} \text { Price }}
$$

The calculation of the marginal MER for electricity in this paper is based on the logic applied in operation of the CEP, namely that the combined cycle units are operating at full capacity. For additional electricity, i.e., for the next MW, the electricity will come from the grid and

$$
(M E R)_{\text {Elec }}=(M E R)_{\text {Grid }}
$$

The MER for steam (the next kilo-pound of steam) under the condition in which steam is available from wasted steam from the SCB, i.e., all summer and significantly during shoulder seasons,

$$
(M E R)_{\text {Steam }}=0
$$

Under the condition in which excess steam is not available from the SCB, i.e., in the winter, steam will be generated by the duct burner and

$(M E R)_{\text {Steam }}=[$ Emission Coeff $] x[\text { Fuel conv.factors }]_{D B / F u e l}$ to steam

The approach taken in this paper for calculating electric MERs follows. Due to cogeneration constraints, any reduction in electric generation from the gas turbines would reduce steam generation and could lead to a shortfall in steam available to meet demand. As a result, the calculation of MER, i.e., the reduction in $\mathrm{CO}_{2}$ per MW reduction in generation, is represented by two components. The first is the reduction in fuel use and the second reflects the offsetting and incremental use to produce the lost steam. This results in: 


$$
\begin{aligned}
\left(M_{\text {MER }}\right. & \\
& =\left(\Delta C \mathrm{CO}_{2}\right)_{-} \text {from reduction of } 1 \mathrm{MW} \text { of generation } \\
& +\left(\Delta \mathrm{CO}_{2}\right)_{\text {from impact of added generation for steam }}
\end{aligned}
$$

The emissions impact of the first component (reduction in generation) can be calculated using the operational heat rates of either the gas turbines or the combined cycle plant depending on how the small MW reduction is achieved. The additional steam of the second component can be generated using duct burners that always have an operating margin - this emissions impact is calculated based on the duct burner heat rate and the amount of compensatory heat injection required by the steam cycle.

Based on the above, the Cornell CEP MERs can be calculated by first establishing distinct operating scenarios that are expected to have different MERs and second by determining the appropriate net emissions impact for each.

\section{Operation of the CEP}

Figure 1 provides an overview of the CEP.

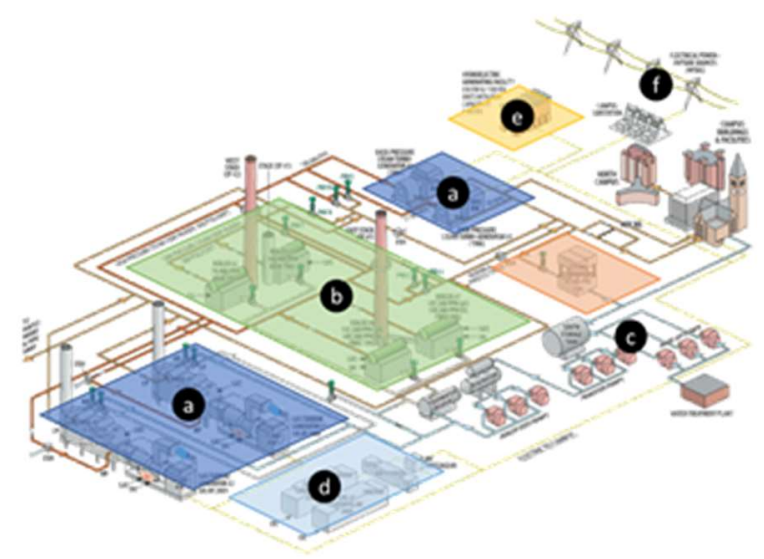

Figure 1: Cornell Central Energy Plant

The elements of the CEP are:

a) Combined Cycle Plant (2GT x $1^{\mathrm{ST}}$, dual pressure, $\mathrm{w} /$ duct burner) with a nominal rating of $\sim 35 \mathrm{MW}$. Responsible for 'base load' electricity and steam production. Dual fuel.

b) Package Boilers (4x) supplementary steam production vis-à-vis additional electric generation. Dual fuel.

c) Balance of Plant (BOP) - Shared facilities. Consumes grid imported auxiliary power.

d) Emergency Diesel Generators - (2x) nominal rating of $1 \mathrm{MW}$ each. Backup operation only. e) Hydropower Plant - 2 MW. No emissions.

f) Campus Substation - interconnects campus to the grid at $115 \mathrm{kV}$.

Figure 2 Indicates the annual demand versus supply of electricity provided by the CEP, indicating the residual beyond internal demand, which is sold into the New York wholesale market.

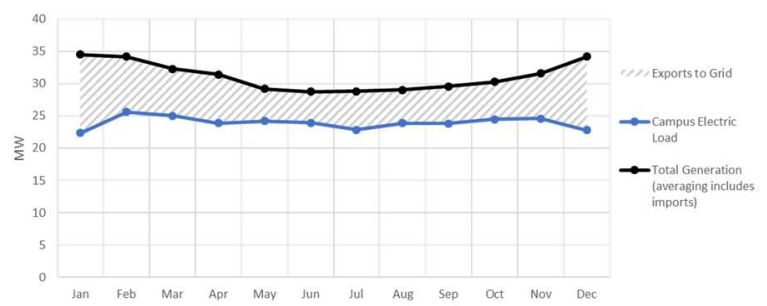

Figure 2: Electricity Supply and Demand

Figure 3 shows the supply and demand position for thermal energy with the area between the curves representing steam energy that is sent to a condenser, i.e., waste heat during the warmer months of the year.

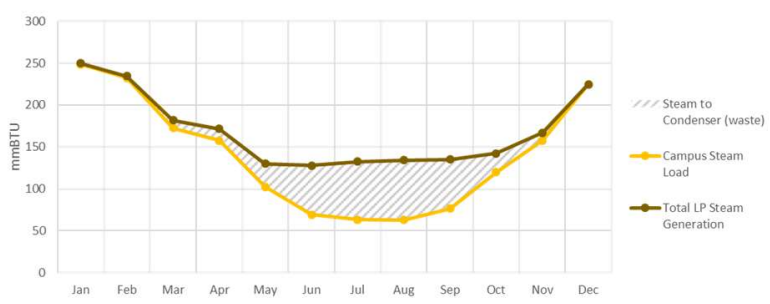

Figure 3: Thermal (Steam) Supply and Demand

The principle operating focus of the CEP is to utilize the high efficiency combined cycle units as base load with excess electric sales going to the NY wholesale market. This decision is based on the assessment that it is more economically efficient for the university to generate its electricity than to operate in a thermalpriority mode and buy some of its electricity from the market. When thermal energy in excess of that produced by the combined cycle units is required, the existing duct burners and package boilers available within the CEP are employed.

The current strategy for allocation of emissions to the production of electricity and steam at the cogeneration facility is based on the BTUs of fuel consumed.

$$
\begin{aligned}
& \text { Frac }_{\text {elec }}=\left(\frac{B T U_{\text {elec }}+B T U_{\text {scb }}}{B T U_{\text {stm }}+B T U_{\text {elec }}+B T U_{\text {scb }}}\right) \\
& \text { Frac }_{\text {stm }}=\left(\frac{B T U_{\text {stm }}}{B T U_{\text {stm }}+B T U_{\text {elec }}+B T U_{\text {scb }}}\right)
\end{aligned}
$$


At the margin, the next MW of electricity, and therefore the marginal unit of emissions (MER), will be sourced from the Grid.

During the summer period the marginal unit of steam $r$ is available from steam that would otherwise be sent to the SCB, i.e., would be wasted. Any electricity that can be generated from this steam would not have required additional thermal energy. For this reason, the marginal unit of electricity will have no MER. During the winter period when the gas turbines are fully loaded, all pf the steam is used for space heating on campus.

The paper that follows discusses and provides empirical examples of each of these MER calculation procedures as well as the formulation and case analyses of the optimal operation of a complex institutional cogeneration facility, the Cornell Central Energy Plant.

\section{Operating Scenarios at CEP 5.1. Summer Operation}

In the summer months, the Combined Cycle (CCGT) units are fully operational, and the steam boilers and duct burners are off.

- MW reduction is achieved by reducing the CCGT load by $1 \mathrm{MW}$. Reduction in fuel use ("Y") is calculated based on the operating heat rate of the CCGT plant.

- Any steam required is available from excess steam that otherwise is sent to the SCB and therefore requires no additional fuel use.

- Emissions are calculated by multiplying the change in fuel use by the $\mathrm{CO}_{2}$ emissions rate

(MER CEP/Elec $_{\text {Summer }}$

$=(\text { Heat Rate })_{\text {GT,Operating point } .} \times$ Emission Coeff

\subsection{Winter Operation}

In the winter months, the Combined Cycle units are fully operational with boilers and duct burners available. There is no waste steam.

- MW reduction is achieved by reducing the GT load by $1 \mathrm{MW}$. Reduction in fuel use ("Y") is calculated based on the operating heat rate of the GT.

- The loss in GT exhaust heat must be compensated by the duct burners ("Z") which is calculated using the heat requirement and DB heat rate

- Emissions are calculated by multiplying the net change in fuel use by the $\mathrm{CO} 2$ emissions rate

$\left(M E R_{C E P} / \text { Elec }\right)_{\text {Winter }}=(\text { Heat Rate })_{G T, \text { operating point }}$

$\times$ Emission Coeff $\times\left(1-\left(1-E f f_{G T}\right) \times\right.$ Heat Rate $\left._{D B}\right)$

\subsection{Historical Operation Trends}

The historical operations of the CEP were evaluated in order to categorize the frequency of individual operating states. Electric Priority ("summer") hours were placed into categories based on steam being on or off, and gas turbine operation high, medium or low as shown in figure 4 . The values under the six categories represent the percentage of hours from 2015 to 2018.

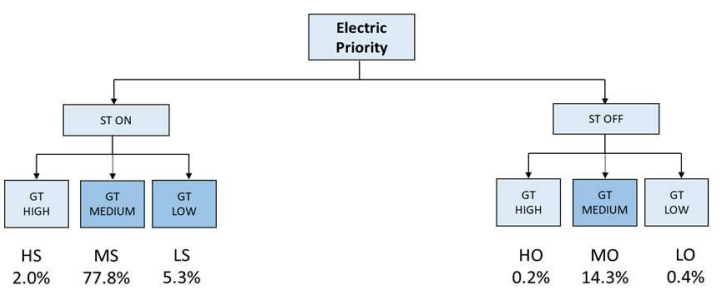

Figure 4: Electric Priority operating \%

Figure 5 shows the configuration tree for Steam priority, the states that exist, the percentage of hours from 2015 to 2918 in each of those states.

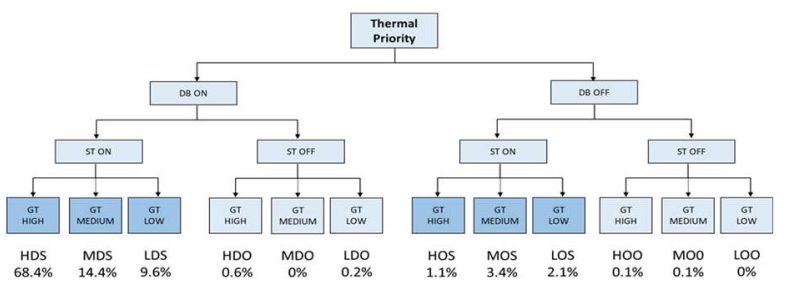

Figure 5: Steam Priority operating \%

Plant MERs under electric priority can be calculated by determining the reduction in fuel use ' $\mathrm{X}$ ' (MMBTU) to achieve a $1 \mathrm{MWh}$ reduction in electric output. This reduction can be calculated by estimating the marginal fuel-to-electric conversion efficiency of the CEP for each configuration.

We estimated this conversion efficiency by setting up a single linear regression model that regresses the total electricity generation ( $\mathrm{E}_{\mathrm{CCGT}}$ ) to the fuel input to different generators (Fuel ${ }_{\mathrm{GT}}$, Fuel $_{\mathrm{DB}}$, Fuel Boilers$_{\text {). Since }}$ the boilers and duct burners are not in operation under electric priority, the regression reduces to a single term. The estimated coefficient of regression $\left(\beta_{\mathrm{e}, \mathrm{gt}}\right)$ is equal to the marginal fuel-to-electric conversion efficiency in MWh per MMBTU. The constant $(\alpha)$ is not required.

$$
E_{C C G T}=\alpha+\beta_{\theta, g t} \text { Fuel }_{G T}
$$

Regression analysis was used on each subset of data for each configuration identified in Figure 4 year by year. The MER calculated fuel emission coefficient for electric priority is 0.053302 thousand tons/MMBTU. 
Using a similar but more complex set of regression relationships, the MER for steam priority was calculated to be 0.05302 thousand tons per MMBTU.

Applying the MER coefficients above to the hourly operating output of the CEP provided the ability to evaluate the monthly, 24 hour average, on and off peak emissions as shown in Figure 6 below.

\section{Determining the NYISO MERs at the substation closest to Cornell CEP}

The closet substation to Cornell's CEP is Maple Avenue in Ithaca. Returning to a prior point, the Marginal Emission Rate for any location in the NYISO is the change in $\mathrm{CO}_{2}$ emissions in the entire grid for a 1 MW change at a given location and moment of time, accounting for the re-dispatch needed to accommodate the positive or negative change in load.

$$
M E R_{\text {node }}=\frac{\Delta\left(\mathrm{CO}_{2}\right)_{\text {system }}}{\Delta(\text { Demand })_{\text {node }}}
$$

Calculation of the MER for the Maple Avenue substation was based on the use of the Production costing tool ENELYTIX (powered by PSO). ENELYTIX is a security constrained unit commitment and dispatch tool that has been widely used by the authors in multiple evaluation exercises including the economic valuation of projects bid into RFP processes in Massachusetts and Rhode Island and reported in HICSS 52 [11].

For the NYISO, the ENELYTIX model was first benchmarked against the LBMPs for the period 2015 to 2018 to assure model consistency with historical data. The benchmark, based on available public data, demonstrated that the ENELYTIX structure reproduces monthly peak, off peak and average LBMP values for each of the zones in the NYISO system. Where differences occurred, they were small and primarily in the shoulder months.

\section{Comparison of the NYISO MER with the MER of the CEP}

Comparison of the NYISO MER with that of the CEP was done by attributing the MER coefficient as described in section 4 above to each hour of operation of the CEP compared with the modeled hourly MER for the NY ISO at the Maple Avenue substation. The comparative results are shown in Figure 7 below and demonstrate that CEP's monthly MER never exceeded those of the NYISO when operating in steam (winter) mode. In summer months, the conclusion is slightly different in that for the 24-hour average, the CEP accounted for fewer marginal tons of carbon per MWH than did the NYISO in nearly all summer months. Focusing on the summer, (see Figure 8) on-peak hours the results are more interesting in that in only one month of 2016 and (June) and one of 2017 did the CEP emit more tons/MWH than was attributable to the NYISO at the Maple Avenue bus.

\section{Conclusions}

This paper has demonstrated that it is both possible and desirable to calculate the Marginal Emission Rate of a major cogeneration facility and compare that to the nodal MER for the organized market from which the cogeneration facility would otherwise consume electricity.

The conclusions of our analysis of the marginal emissions of the CEP compared to those of the Maple Avenue substation, the point from which Cornell both receives and exports its power, for both the historical period of 2015 to 2019 and in terms of our ability to forecast the MER going forward for 2019 and 2020 are striking and clear.

- $\quad$ For the period of 2015 to 2018 for which we have evaluated the operation of the CEP, the marginal emissions of the CEP have consistently been below those of the NYISO calculated at the Maple Avenue substation.

- $\quad$ Forecasting both the operation of the CEP and that of the NYISO forward to 2019 and 2020, the conclusion is the same; the marginal emission rate of the CEP will be lower than that of the NYISO for energy delivered at the Maple Avenue substation.

While this analysis does not look beyond 2020, there are a number of conclusions that can be extrapolated from trends in New York that will be the principle factors that determine whether these conclusions will hold going beyond 2020 .

The first of these is the likely evolution of the New York power system toward greener production. New York has committed to arriving at a point of zero carbon emissions from the electric power sector by 2040. The first steps of the ambitious goal have been taken in the commitment to two projects totally $1700 \mathrm{MW}$ of offshore wind with online dates of 2024 that represent the first step toward a goal of $9000 \mathrm{MW}$ by 2035. A second evolution is the closure of the Indian Point 
Nuclear units 2 and 3 scheduled to occur in 2020 and 2021.

The development of significant offshore wind and the closure of Indian Point are largely offsetting from the perspective of average emissions but will tend to work in the same direction in terms of their impact on marginal emissions. Independent of other events, offshore wind would reduce the grid's carbon emissions on average. However, without a significant increase in the price of natural gas that could bring back coal-fired generation, the primary marginal emission source for the State will remain efficient natural gas fired single cycle and combined cycle units.

The closure of Indian Point units 2 and 3 will remove a significant block of non-carbon emitting generation that will need to be replaced in order to maintain the operational reliability and efficiency of the New York system. That added capacity will, in the intermediate run, also come from efficient natural gas generation that will dominate the marginal emission source.

The overarching conclusion looking beyond 2020 is that despite what will be significant changes to the generating stock of New York State, the marginal emission source will continue to be from natural gas fired simple cycle and combined cycle units. From the perspective of the comparative evaluation of the CEP to the MER of the NYISO, there are unlikely to be changes in the operating logic of the CEP or in the NYISO generation mix at the margin that will alter the conclusions above.

\section{References}

[1] Deetjen, Thomas A., and Inês L. Azevedo. "ReducedOrder Dispatch Model for Simulating Marginal Emissions Factors for the United States Power Sector." Environmental science \& technology 53.17 (2019): 10506-10513.

[2] Chen, Y., J. Sijm, B.F. Hobbs, W. Lise "Implications of $\mathrm{CO}_{2}$ Emissions Trading for Short-run Electricity Market Outcomes in Northwest Europe," Journal of Regulatory Economics, 2008, 34(3): pp. 251-281.

[3] Joshua S.Graff, Matthew Zivin, Erin T.Mansur, "Spatial and temporal heterogeneity of marginal emissions:

Implications for electric cars and other electricity-shifting policies" Journal of Economic Behavior \& organization, November 2014 pp $248-268$.

[4] Stephen Holland and Erin Mansur "Is Real-Time Pricing Green? The Environmental Impacts of Electricity Demand Variance", Review of Economics and Statistics, Volume 90, Issue 3, August 2008, pp. 550-561.

[5]See https://www.watttime.org
[6]Pablo Ruiz and Aleksandr Rudkevich, "Analysis of Marginal Carbon Intensities in Constrained Power Networks." IEEE Proceedings of the 43rd Hawaiian Conference on System Sciences, January 2010.

[7] Aleksandr Rudkevich and Pablo Ruiz, "locational Carbon Footprint of the Power Industry: Implications for Operations, Planning and Policy Making" in Q. P. Zheng et al (eds.) Handbook of Co2 in Power Systems DOI 10.1007/978-3-64227431-2_8 Springer Verlag Berlin Heidelberg, 2012

[8]Aleksandr Rudkevich, Pablo Ruiz and Rebecca Carroll, "Locational Carbon Footprint and Renewable Portfolio Policies: A theory and its Implications for the Eastern Interconnection of the US. IEEE Proceedings of the $44^{\text {th }}$ Hawaiian Conference on System Sciences, January 2011.

[9] Ethan D Avallone "LBMP Carbon Impact (LBMPc) Calculation and Transparency" Posted on the web site of NYISO October 29, 2018 and reposted November 16, 2018.

[10] S. A. Newell, R. Lueken, J. Weiss, K. Spees, P. DonohooVallett. T. Lee, "Pricing Carbon into NYISO's Wholesale Energy Market to Support New York's Decarbonization Goals. Prepared for the NYISO by the Brattle Group, April 10, 2017

[11] R. Tabors, J. R. Hornby, H. He, X. Li, N. Kumthekar, A. Rudkevich, S. Englander "Nodal Project Evaluation Applied to Large-Scale Renewable Energy Procurement: A case Study of Massachusetts, Proceedings of the 52nd Hawaiian Conference on System Sciences, January 2019. 
Figure 6: Monthly historic and projected MERs
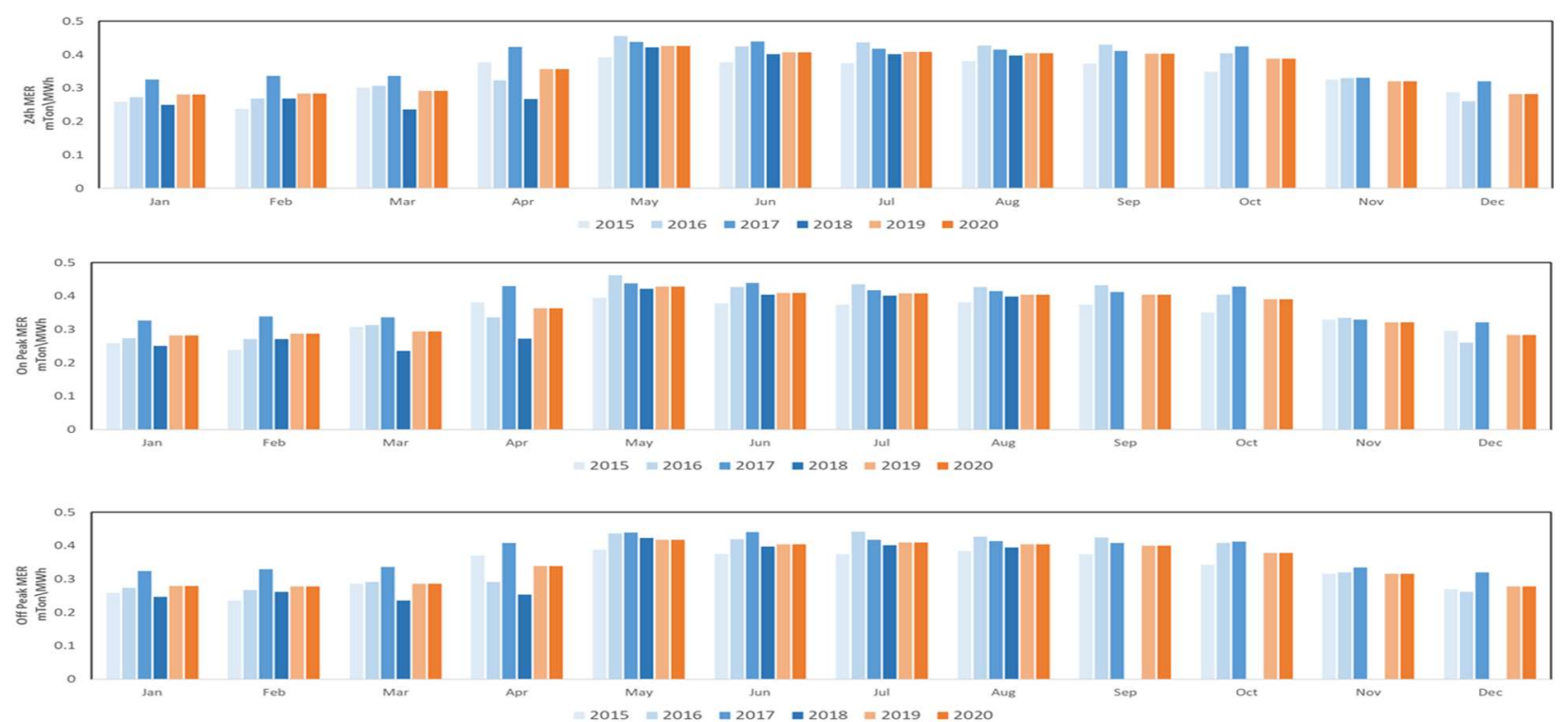

Figure7. Grid MER vs CEP MER. Historical analysis.

$2015-2018$
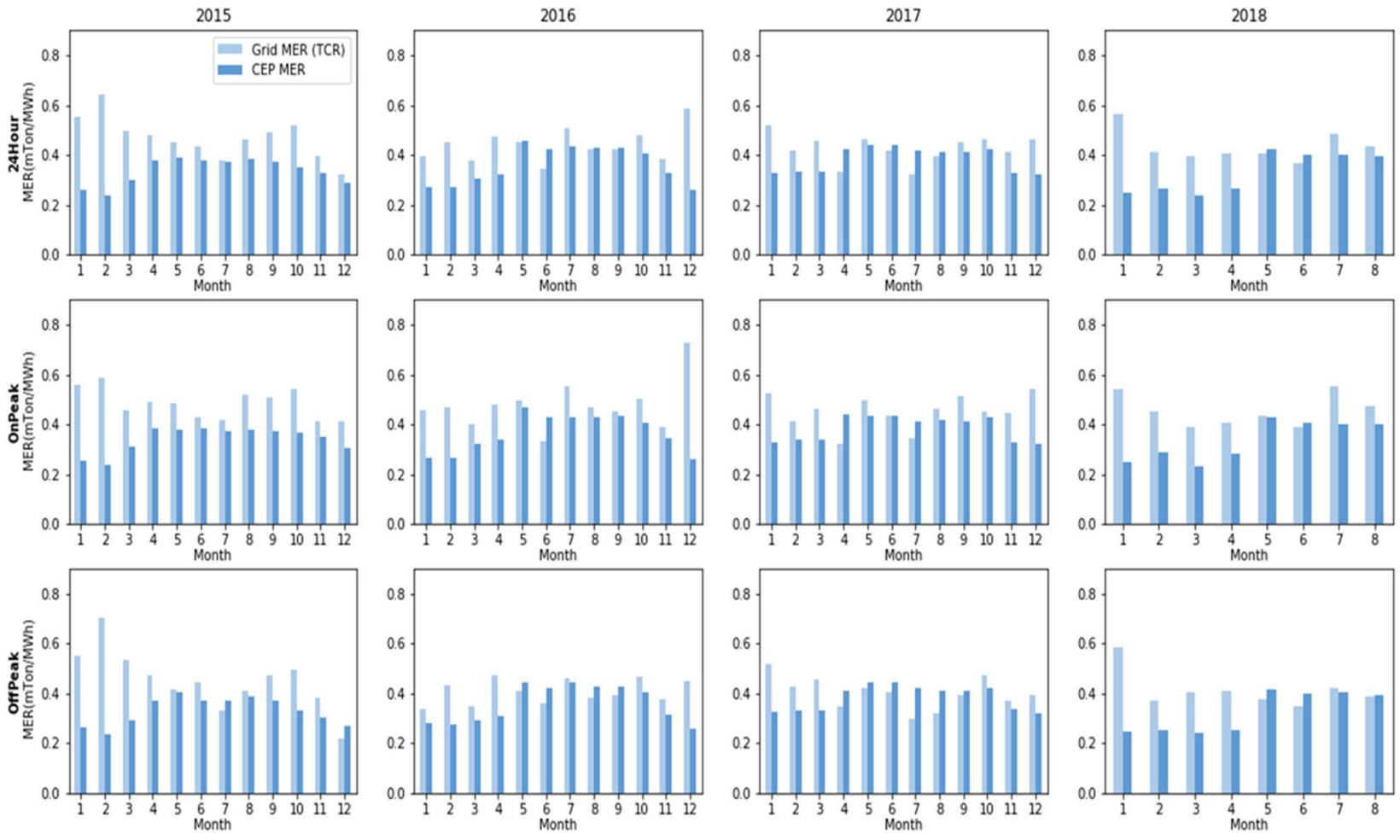